\title{
New ligation technique using a double loop clip without adhesive for ulceration following endoscopic submucosal dissection of the colon
}

Various ligation techniques for post-endoscopic submucosal dissection (ESD) ulceration have recently been reported [1 5]; however, no technique has been established owing to the complexity involved and the fact that an expensive device is required. We devised a new ligation technique using a double loop clip (D-L clip) without an adhesive agent for ulceration following ESD of the colon.

First, a standard clip (HX-610-90; Olympus, Tokyo, Japan) is attached to a rotatable clip-fixing device. The clip is deployed, and before deployment is completed, a thread, which is tied loosely in advance, is passed through the portion intersecting the clip arm at the base of the clip and tied. Next, a double loop of appropriate length is created using the remaining thread. The clip is drawn back again into the rotatable clip-fixing device. This completes the D-L clip without the use of an adhesive agent ( $\triangleright$ Fig. 1). The $\mathrm{D}$-L clip is applied to the proximal side of the post-ESD ulcer area ( $\triangleright$ Fig. 2 ). Clipping of the mucous membrane on the distal side is performed by applying a different clip to the proximal or distal loop line in each situation. We usually pick up the proximal loop line. A clip is then added to tighten the ligation, thereby completing the ligation ( $\vee$ Video 1 ).

We previously used a single loop clip, but it was sometimes difficult to pick up the
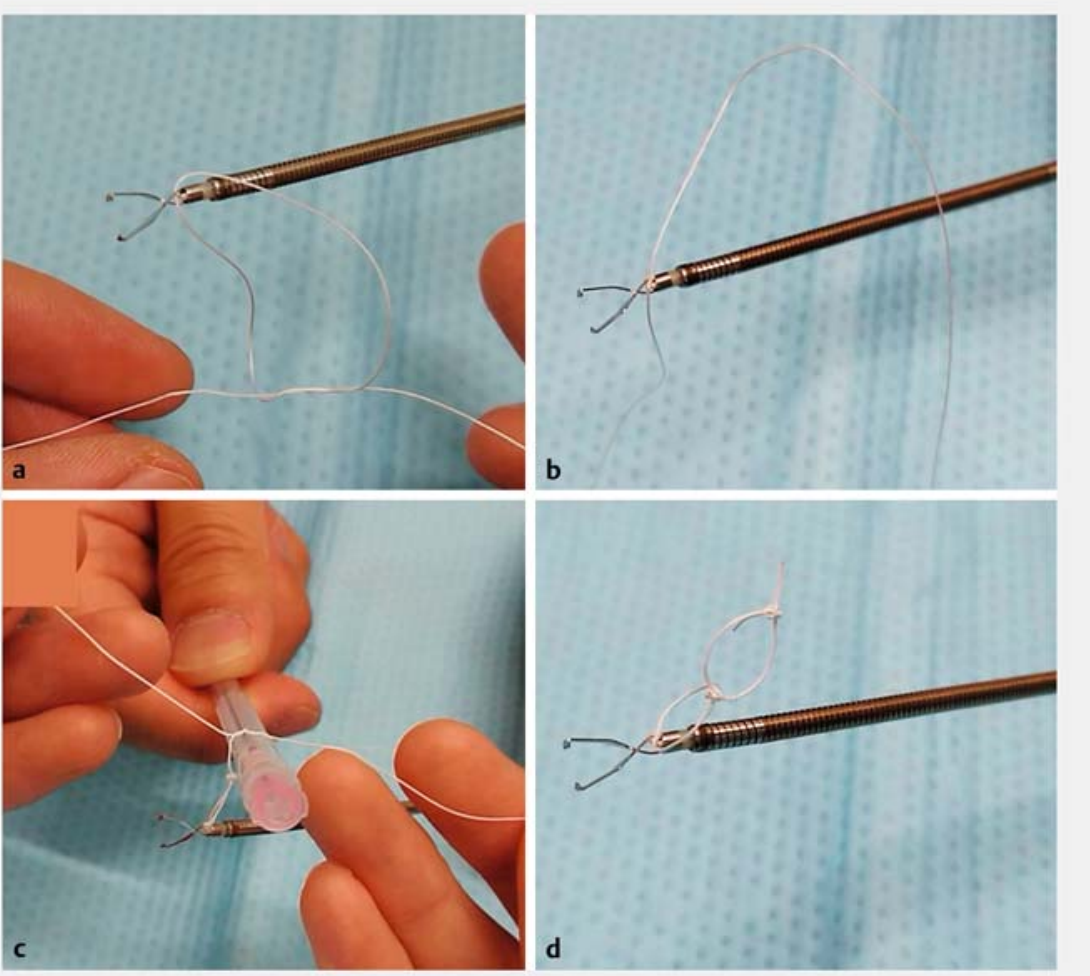

loop line, because the loop line was crumpled. In this new technique, the weight of the distal loop moderately extends the proximal loop line. We can easily pick up the proximal loop line, and if we cannot pick up one loop line, we can try to pick up the other loop line.

The ligation technique using a D-L clip without an adhesive agent is a useful technique that is simple and cost-effective.

Endoscopy_UCTN_Code_CPL_1AJ_2AD

Competing interests

None

The authors

Satoshi Abiko, Ayumu Yoshikawa, Kazuaki Harada, Naoki Kawagishi, Itsuki Sano, Hisashi Oda, Takuto Miyagishima

Department of Gastroenterology, Kushiro Rosai Hospital, Kushiro, Japan

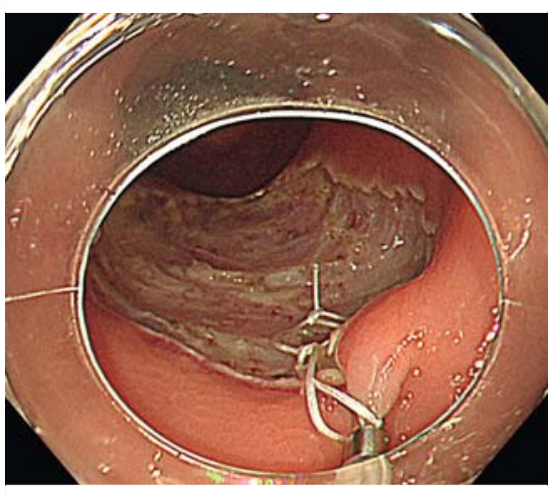

- Fig. 2 Ulceration following endoscopic submucosal dissection (ESD) of the colon ( $34 \mathrm{~mm}$ in diameter). The D-L clip is applied to the proximal side of the post-ESD ulcer area. 


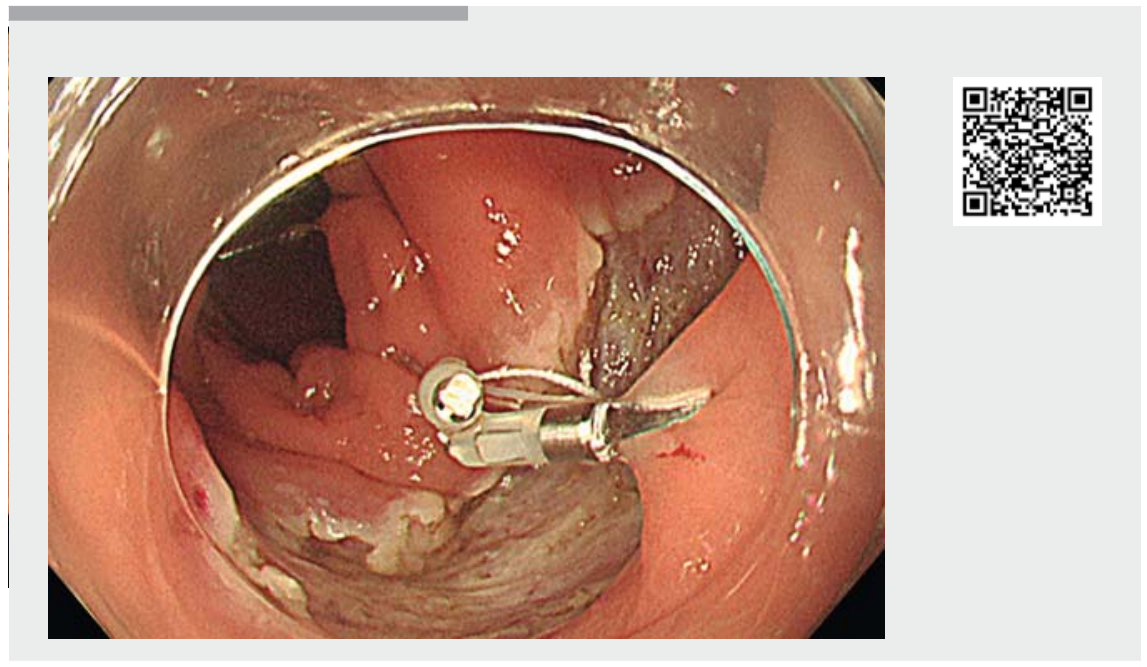

Video 1 Method for making a D-L clip without an adhesive, and demonstration of the ligation technique using the $\mathrm{D}$ - $\mathrm{L}$ clip for ulceration following endoscopic submucosal dissection of the colon.

\section{Corresponding author}

\section{Satoshi Abiko, MD}

Department of Gastroenterology, Kushiro Rosai Hospital, 13-23, Nakazono-cho, Kushiro 085-8533, Japan

Fax: +81-154-257308

abiko1982@gmail.com

\section{References}

[1] Sakamoto N, Beppu K, Matsumoto K et al. "Loop clip", a new closure device for large mucosal defects after EMR and ESD. Endoscopy 2008; 40: E97-98

[2] Mori H, Kobara H, Nishiyama $\mathrm{N}$ et al. Simple but reliable endoscopic sliding closure with ring-shaped surgical thread after endoscopic submucosal dissection. Endoscopy 2015; 47: E428-E429

[3] Nomura T, Kamei A, Sugimoto $S$ et al. New closure method for a mucosal defect after endoscopic submucosal dissection: the clip- on-clip closure method. Endoscopy 2018; 50: $547-548$

[4] Horii T, Ikehara H, Gotoda T et al. Endoscopic closure method using a dental floss O-ring for mucosal defect after endoscopic resection. Dig Endosc 2019; 31: e15

[5] Akimoto T, Goto O, Nishizawa T et al. Endoscopic closure after intraluminal surgery. Dig Endosc 2017; 29: 547 - 558

\section{Bibliography}

DOI https://doi.org/10.1055/a-0979-4027

Published online: 13.8.2019

Endoscopy 2020; 52: E20-E21

(c) Georg Thieme Verlag KG

Stuttgart · New York

ISSN 0013-726X

\section{ENDOSCOPY E-VIDEOS}

https://eref.thieme.de/e-videos

口居 Endoscopy E-Videos is a free access online section, reporting 回和: on interesting cases and new techniques in gastroenterological endoscopy. All papers include a high quality video and all contributions are freely accessible online.

This section has its own submission website at https://mc.manuscriptcentral.com/e-videos 